\title{
Beyond the glass ceiling: participation in decision making in the public domain by Swarna Jayaweera, Chandra Gunawardena and Indika Edirisinghe (CENWOR, 2008)
}

\section{Why women rarely make it to the top? Reflections on a new study investigating factors inhibiting career advancement of women in Sri Lanka}

Reviewed by Kalinga Tudor Silva*

Department of Sociology, Faculty of Arts, University of Peradeniya
Sri Lanka produced the world's first female Prime Minister. In addition, the fourth executive President of the Democratic Socialist Republic of Sri Lanka was a woman and for a while both the President and the Prime Minister of Sri Lanka were women from the same political dynasty. And yet the fact remains that Sri Lanka has one of the lowest presence of women in the legislative assemblies from the national to the local government levels and relatively lower representation of women in the highest level of bureaucracy and corporate governance in spite of a remarkably high participation of women in higher education. This is the paradox that "Beyond the Glass Ceiling: Participation in Decision Making in the Public Domain", a recent publication of the Centre for Women's Research (CENWOR), a leading research centre in the country seeks to resolve. The study marshals a large body of primarily quantitative information collected through a survey conducted among the staff in public and private sector agencies in order to assess the situation with regard to gender distribution in these higher echelons of society and examine why females' rise to the top has been hampered in spite of notable achievements in some sectors.

Authored by Swarna Jayaweera, Chandra Gunawardena and Indika Edirisinghe, three lead researchers attached to CENWOR, this publication raises a number of important analytical and policy relevant questions regarding underrepresentation of women at the highest level of politics, administration and corporate governance.
The authors state that "The present study was the outcome of CENWOR's concern regarding the under representation of women in the highest level decision making positions in the public and private sectors juxtaposed with the fact that $53 \%$ of the university student population are women and that they are well represented in professional educational courses except in the field of technology." (page 1). While women are neither excluded nor discouraged from education and employment in general, their rise to the top in the public sphere inclusive of corporate governance seems to have been blocked or stifled through some mechanisms. The authors approach this issue using the notion of "glass ceiling" invented by some American social scientists in order to explain why white heterosexual men essentially control and dominate top management in business in American society in spite of its much publicized commitment to openness, achievement orientation in place of ascription, pluralism and multiculturalism. "A ceiling is suggested because persons outside the dominant demographic group are supposedly limited in how far they are able to advance in the organizational ranks; the ceiling is "glass" (transparent) because the limitation is not immediately apparent. The glass ceiling is distinguished from formal barriers to advancement". In other words when this notion is applied to women in Sri Lanka they are experiencing a seemingly non-existent barrier which is nevertheless real and more or less impenetrable when they try to climb to the top layer in the social and political ladders. The important thing is that the glass ceiling is completely 
external to the people who are trying to move up and it does not rest within the persona of the individuals concerned in any sense. Whether this describes the true situation with regard to why women rarely make it to the top may be questionable in so far as it excludes any element of women's self inhibition due to socialization and other factors, for instance, in running for political office, operating of course side by side with a multiplicity of inhibiting factors and serious challenges they face in gaining power and overcoming discrimination in private and public domains and prevailing gender stereotypes in society.

Chapter One to Three of this book provide an introduction to the book, present the framework for analysis derived from the larger body of literature in social sciences and outlines the methodology for the survey of personnel in public and private sectors that formed the empirical foundation of this work. Chapter Four deals with the macro picture relating to gender distribution in higher echelons in the public sector, corporate sector and in small and medium enterprises largely using available secondary data. Chapters Five to Nine comprise the main body of the book in terms of presentation and analysis of primary data relating to gender distribution at management levels (Chapter Five) and factors affecting upward mobility of women in different sectors (Chapters Six to Nine). The Concluding Chapter (Chapter Ten) draws conclusions regarding why women are inhibited in their career advancement and draws policy implications for addressing obstacles to career advancement and empowerment of women.

Some of the key findings of this study are as follows:

First, the percentage of women in SriLanka Administrative Service (SLAS) increased from $7.6 \%$ in 1979 to $35.4 \%$ in 2007. There has been a corresponding increase in percentage of class 1 officers in SLAS who are women from a mere 1.8 in 1979 to 27.2 in 2007. However, in 2007 only $8.9 \%$ of Secretaries of Ministries were women. On the other hand in $200624 \%$ of additional secretaries in the Ministries were women. Whether this is merely a reflection of time lag in women's advancement to top positions in public administration or an outcome of a structural gender inequality in society requires closer scrutiny than is attempted in the study.

Second, in various other administrative and professional employments too there has been a gradual increase in the proportion of women in recent years but certainly they have not caught up with men when it comes to the highest levels of decision making in these sectors. For instance, in the judiciary only $8.2 \%$ of the judges of the
Supreme Court, Appeals Courts and High Courts were women as of year 2000 .

Third, the private sector actually has a much more skewed gender distribution at the highest management levels. For instance, only $6.1 \%$ of Directors in Boards of Companies registered at the Colombo Stock Exchange in 2005 were women. Whether this is due to a voluntary choice on the part of women to keep away from top levels of corporate governance or an outcome of a glass ceiling that male heads of the private sector have carefully established in order to prevent women from taking over their positions must be explored further, perhaps through different research techniques such as observational research in selected companies.

Fourth, professionally and educationally women were often better qualified than men in comparable grades in the public sector, while this was reversed in statutory bodies and the private sector. This is perhaps one of the most important discoveries of this study. Yet, why this is so is not fully explored in this study in spite of its central importance to the theme of inhibitions for career advancement of women in different sectors. This indicates that merit factor is not a constant in positioning of women in the various sectors and that gender is an intervening variable that interferes with matching of employment with merit in diverse sectors. The fact that women workers in the public sector are often better qualified than male workers in comparable grades may be a concrete example of gender-based discrimination in career advancement in this sector. On the other hand, women may be clustered in certain sectors in the public sector such as teaching, nursing and secretarial work due to prevailing gender stereotypes and women's own choice of employment in keeping with such stereotypes.

Fifth, in spite of the apparent gender inequality in the work force, level of job satisfaction does not appear to be vastly different between men and women in the different sectors.

Sixth, in line with merit profile of men and women workers in the public sector noted above, reported experience of discrimination in the public sector work places was considerably higher among women (43.4\% of women compared to $33.5 \%$ of men).

Seventh, conflicting demands from work and family affected men and women in all sectors of employment, but the gender gap with regard to reported dual burden was most significant in public sector followed by statutory bodies and private sector. Qualitative information 
provided however, indicate that the dual burden is more of a problem for professional women whose child care and other reproductive responsibilities hamper their career advancement beyond a particular level.

Finally, among the specific factors inhibiting women's advance to higher levels of decision making and rise to leadership positions were sexual harassment, relative disobedience of male subordinates to female managers, lack of female role models in leadership positions and the sacrifices the women are sometimes expected to make in dual career families and in the care of children, sick and elderly.

On the whole this is a welcome addition to the social science literature and social policy dialogue in Sri Lanka. The work is very much policy and practice oriented and is in keeping with the vision, mission and the advocacy function of CENWOR. The analysis of the statistical information presented is straightforward and convincing for the most part, but it could have been made analytically more rigorous by application of proper statistical procedures such as test of significance, for instance, when comparing reported experience of discrimination among men and women. The study only uses bits and pieces of qualitative information, for instance, in reporting actual experience of discrimination (page 61) and difficulties in dealing with conflicting demands from the family and the work place. In my view the study is too preoccupied with presenting statistical information in tabular form. A more systematic and balanced use of qualitative information in the form of case histories and narratives would have added to the value of the study. Even though the notion of glass ceiling is mentioned in the title of the book and elaborated in the introduction, what actually constitutes the glass ceiling that restricts women's rise to leadership positions in the work place and the community at large is not discussed in the body of the book and in the conclusion. Related phenomena such as heavy presence of armed women in the LTTE and JVP in its militant stage and the emergence of female priesthood in alternative religious spheres such as Meheni Sasna and in deity cult have escaped the attention of the researchers due to their preoccupation with the analysis of survey data to the relative neglect of larger social processes reflecting to some extent social protest by women against patriarchy and social oppression of women. Moreover, issues about subjectivity of women and their inclination to remain within spaces and limits imposed by society may be partly responsible for their failure to climb to the top, certainly much more than is recognized in this study. In spite of these limitations this book certainly addresses important analytical and policy issues relating to why women in Sri Lanka are a long way behind men in career advancement in spite of decades of free education, universal franchise and women's activism. Those engaged in gender studies, development work and social policy can ill afford to disregard the findings of this important publication. 